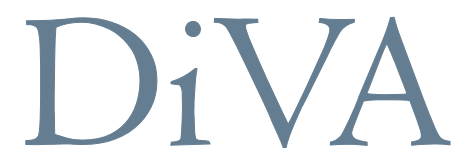

http://uu.diva-portal.org

This is an author produced version of a paper published in Natural Resources Research. This paper has been peer-reviewed but does not include the final publisher proof-corrections or journal pagination.

Citation for the published paper:

Höök, M., Junchen, L., Noriaki, O. \& Snowden, S.

"Descriptive and predictive growth curves in energy system analysis"

Natural Resources Research, 2011, Vol. 20, Issue 2: 103-116

URL: http://dx.doi.org/10.1007/s11053-011-9139-z

Access to the published version may require subscription. 
Published in Natural Resources Research

Volume 20, Issue 2, June 2011, Pages 103-116

http://dx.doi.org/10.1007/s11053-011-9139-z

\title{
Descriptive and predictive growth curves in energy system analysis
}

\author{
Mikael Höök ${ }^{1}{ }^{*}$, Li Junchen ${ }^{2}$, Noriaki Oba ${ }^{1}$, Simon Snowden ${ }^{3}$ \\ Contact e-mail: Mikael.Hook@fysast.uu.se \\ ${ }^{1}$ Uppsala University, Global Energy Systems, Department of Physics and Astronomy, Box 535, \\ SE-751 21, Lägerhyddsvägen 1, Sweden, http://www.fysast.uu.se/ges \\ ${ }^{2}$ China University of Petroleum - Beijing, School of Business Administration, 18 Fuxue Road, \\ Changping, Beijing, China \\ ${ }^{3}$ Management School, University of Liverpool, United Kingdom
}

\section{Abstract}

This study reviews a variety of growth curve models and the theoretical frameworks that lay behind them. In many systems, growth patterns are, or must, ultimately be subjected to some form of limitation. A number of curve models have been developed to describe and predict such behaviours. Symmetric growth curves have frequently been used for forecasting fossil fuel production, but others have expressed a need for more flexible and asymmetric models.

A number of examples show differences and applications of various growth curve models. It is concluded that these growth curve models can be utilised as forecasting tools, but are do not necessarily provide better predictions than any other method. Consequently, growth curve models and other forecasting methods should be used together to provide a triangulated forecast. Furthermore, the growth curve methodology offers a simple tool for resource management to determine what might happen to future production if resource availability poses a problem. In the light of peak oil and the awareness of natural resources as a basis for the continued well-being of society and mankind, resource management should be an important factor in future social planning.

Key words: Growth curve models, curve fitting, logistic model, resource management 


\section{Introduction}

Reflecting the core of the natural sciences, as well as key principles behind descriptive/predictive curves, is this famous passage by Newton (1726): "For whatever is not deduced from the phenomena must be called a hypothesis; and hypotheses, whether metaphysical or physical, or based on occult qualities, or mechanical, have no place in experimental philosophy. In this philosophy particular propositions are inferred from the phenomena, and afterwards rendered general by induction."

Growth is a common occurrence in many systems ranging from biology to economics. In many other systems, growth is or must ultimately be subjected to some form of limitation. Conceptually this is easy to grasp as the earth is a finite sphere with finite resources and this must ultimately be a limiting factor for all activities within its physical boundaries. The French scientist Verhulst (1838) reasoned that any population subject to growth would ultimately reach saturation level (usually described as the carrying capacity) and, as a function of the environment, that forms a numerical upper bound on the growth process. Many other scientists in disparate fields and disciplines have expressed similar reasoning. This gave birth to the logistic model and a multitude of similar, or extended models, that are all capable of describing bounded growth phenomena (Tsoularis and Wallace, 2002).

All growth that takes place in reality is subject to natural laws. Consequently, it is necessary to study physical properties and phenomenological growth patterns that have been observed in a wide array of systems. Descriptive curve models help analysts understand the underlying physical properties of the system being analysed, and how they contribute to the observed pattern. Additionally, the fine art of forecasting employs a number of predictive curve models to form future projections. Both tools are essential for growth studies regardless of whether it is economic, energy or future oil production growth.

\section{Aim of this study}

The theoretical background, and a closer examination of several of these models are reviewed. A large number of curve models have been developed but this study will focus on the special cases of the very widely applicable Richards model. Those special cases include Brody, Bertalanffy, logistic and the Gompertz curves. Fitting of various curve models, in particular the bell shaped curves, has been frequently used in energy forecasting, especially in fossil fuel studies.

Bardi (2005) found that although bell shaped behaviour is typical for fossil fuel and mineral extraction, the curve is not necessarily symmetric. This finding is also in agreement with empirical data for coal, oil and many other resources that show production peaks, but not necessarily a presence of symmetric curve shapes (Bardi, 2007; Brandt, 2007; Höök and Aleklett, 2010; Höök et al., 2010a). Caithamer (2008) expressed a need to rethink the logistic curve and apply more flexible curve types. This study will also present a simple toolbox with a number of straightforward curves with both symmetric and asymmetric shapes that can be applied to energy system analysis and forecasting.

\section{Theoretical background}

Analysts are frequently exposed to data that changes over time, i.e. a time series. A time series is a sequence of data points, measurements of a variable, which is commonly taken at successive moments in time spaced at uniform intervals, a sample rate. Some examples of time series are the 
daily closing value of the Dow Jones index, the annual production of electricity from hydroelectric plants, and the monthly production of crude oil in the deepwater region of the Gulf of Mexico, or the decennial global discoveries of natural gas.

Time series analysis is comprised of various methods for analyzing time series data to extract meaningful statistics and other characteristics of the data set. Time series forecasting is the use of a suitable model to forecast future events based on known past events, i.e. to predict data points before they are measured. Some examples of time series forecasting are the prediction of future coal production based on historical behaviour and the extrapolation of historical natural gas discovery trends to assess the potential for new discoveries in the future. A few common methods in time series analysis and forecasting are spectral analysis, ARMA/ARIMA-techniques and various trend estimation approaches, such as the fitting of suitable curves. Others authors have summarized time series analysis in greater detail (Hamilton, 1994; Sprott, 2003; Chatfield, 2004).

A common method of dealing with non-seasonal data that displays a trend, in particular annual data, is to fit a suitable curve and use it to describe changes, and to even project future trends. These curve fits can be rather arbitrary, ranging from linear to very complex functions. This section will summarize some key aspects behind curve fitting in energy systems analysis and forecasting. A good understanding of fundamental curve models used for description and prediction is helpful for all energy system analysts. Reliable analysis of trends in energy systems, and how to accurately forecast them, are vital for making strategic decisions.

In energy systems, increasing or decreasing trends (i.e. positive/negative growth) are often seen and may be of great interest. The term "growth curve" originates in biology and its use in this field has long been established. Growth curves are used for a wide array of models useful for describing changes in population, body mass and other parameters that experience growth over time. McArdle (2004) highlights how growth curve analyses are among the most widely studied and well-developed mathematical and statistical techniques in all scientific research, originating from the 17/18th century science.

Many time series methods related to energy production and consumption show trends and levels of saturation that can be equally described by growth curves. However, the use of growth curves in energy studies is fairly recent (Ang and $\mathrm{Ng}, 1992$ ). Hubbert was a pioneer in this field and did important work in the 1960s. After the oil crises in the 1970's growth curves became increasingly common. However, many of these approaches and their fundamentals are often poorly understood. The primary objective of any form of growth curve fit can be descriptive or predictive.

1: Descriptive growth curves aim to describe the time series information with relatively few parameters to characterize the behaviour of the data studied, a form of 'Occam's Razor'. They are phenomenological descriptions of a general behaviour that use suitable parameters to achieve the primary goal, i.e. an understanding of the relationships between the parameters and how they contribute to the observed pattern. Verhulst (1838) originally developed the logistic model to describe a relation between population growth, size of the existing population and available resources. Hotard and Ristroph (1984) described the discovery and production of oil and natural gas at the national level, Silvennoinen and Väänänen (1987) described technology substitution in energy systems, while Ang and Ng (1992) discussed how growth curves can describe interactions in energy resource analysis, energy demand and fuel substitution. 
2: Predictive growth curves can be used to forecast future growth and to determine how the future might unfold dependent upon known limitations in one or many of the curve parameters. This can be done with a single curve or a sum of curves, depending on the situation. Various forms of growth curves have been used for predicting future production of oil (Szklo et al., 2007; Feng et al., 2008), gas (Imam et al., 2004) and coal (Energywatch group, 2007; Höök and Aleklett, 2009; 2010).

The "goodness of fit" is determined by the deviation of actual data points from corresponding points on the curve, i.e. the magnitude of error. This is normally performed through the measurement of the sum of the squares of the differences between the model and the actual data (Root mean square error). It follows naturally that the best fit of a time series with $n$ points is a (n-1) polynomial. However, polynomials of high degree neither have reliable behaviour for extrapolating, nor are the (n-1) estimated parameters likely to hold any physical meaning. Physical models capable of describing observed behaviour or providing outlooks must have a connection to the physical parameters, generally implying that relatively few parameters should be used. However, it is important to understand that simplistic curve fitting are just a mathematical handicraft and an unwary analyst can be drawn to flawed conclusions from parameters that lack proper physical or economic interpretation or mistake economic constraints for physical constraints. Understanding the underlying data and what it actually represents is vital.

In a similar way, using too many curves can end up with the situation where virtually anything can provide a fit with good agreement to the data using a sufficiently large sum of curves (resembling the case of a Fourier series). This may lead to something called "overfitting," i.e. the model describes random errors (or noise) instead of the underlying trend (Guyon and Yao, 1999; Clark, 2004). Overfitting generally occurs when a model is excessively complex, such as having too many variables or cycles in relation to the amount of data available. Adding additional parameters nearly always lead to better fits, regardless of whether the additional parameters are warranted or not. Multicyclic curve models have been used in several studies (Laherrère, 1997; Imam et al., 2004; Nashawi et al., 2010; Patzek and Croft, 2010).

Sometimes it is appropriate to add more curves, such as those to model new cycles in exploration or expansion phases, opening of additional major oilfields or coal mines, etc. Additional curves can also be justified by statistical means if it can be shown that the goodness of fit is improved more than would be expected by simply adding more model parameters, where this typically is done by an F-test (NIST/SEMATECH, 2010). Application of multi-curve models should always be clearly justified and accompanied by proper description of the underlying assumptions, limitations and sensitivities of the curve ensemble.

A model that has been overfit will generally have poor predictive performance as it can exaggerate minor fluctuations in the data. There are a number of statistical methods available for reducing this problem. Cross validation (Stone, 1977; Browne, 2000) is a technique involving the partitioning of a data set into complementary subsets, performing the analysis on one subset and then validating the analysis on the other subset. Statistical regularization (Bickel et al., 2006) is another wide group of methods aimed at handling instabilities associated with fitting a model with a large number of parameters in a sensible fashion. Common sense is in many cases enough to avoid serious problems associated with overfitting. A useful rule-of-thumb is to make sure that each parameter has at least 10 data points (Sorrell and Speirs, 2010). 
Computational difficulty and mathematical tractability vary with the choice of curves and the data set. Many functions are sensitive to frequency and regularity of data. Fitting annual data may work smoothly, whilst monthly data may contain scheduled or unscheduled sudden disruptions that might decrease the quality of the fit significantly. The analyst should always be careful about the data and its intrinsic properties.

Iterative algorithms can be sensitive to the choice of starting values and may not even converge. There is also the risk of obtaining mathematically correct, but physically meaningless, estimates of parameters in numerical calculations. Intrinsic uncertainty in the data under observation is also a problem. For example, the unreliability of reported oil reserves figures introduces interpretation complications and error propagation. In this respect, the golden rule of modelling, "garbage in - garbage out" should always be held dear.

\subsection{General growth modes}

Any growth curve shape can be placed in three different growth mode categories: unbounded; bounded; and bell shaped curves (Figure 1). In bell shaped curves, the increase will eventually turn into decrease after passing through a peak point. Most important is perhaps the distinction that bell shaped curves can be both symmetric and asymmetric. However, it should be noted that the curves displayed in Figure 1 are only examples, and there are a multitude of mathematical functions available for each type of growth mode.

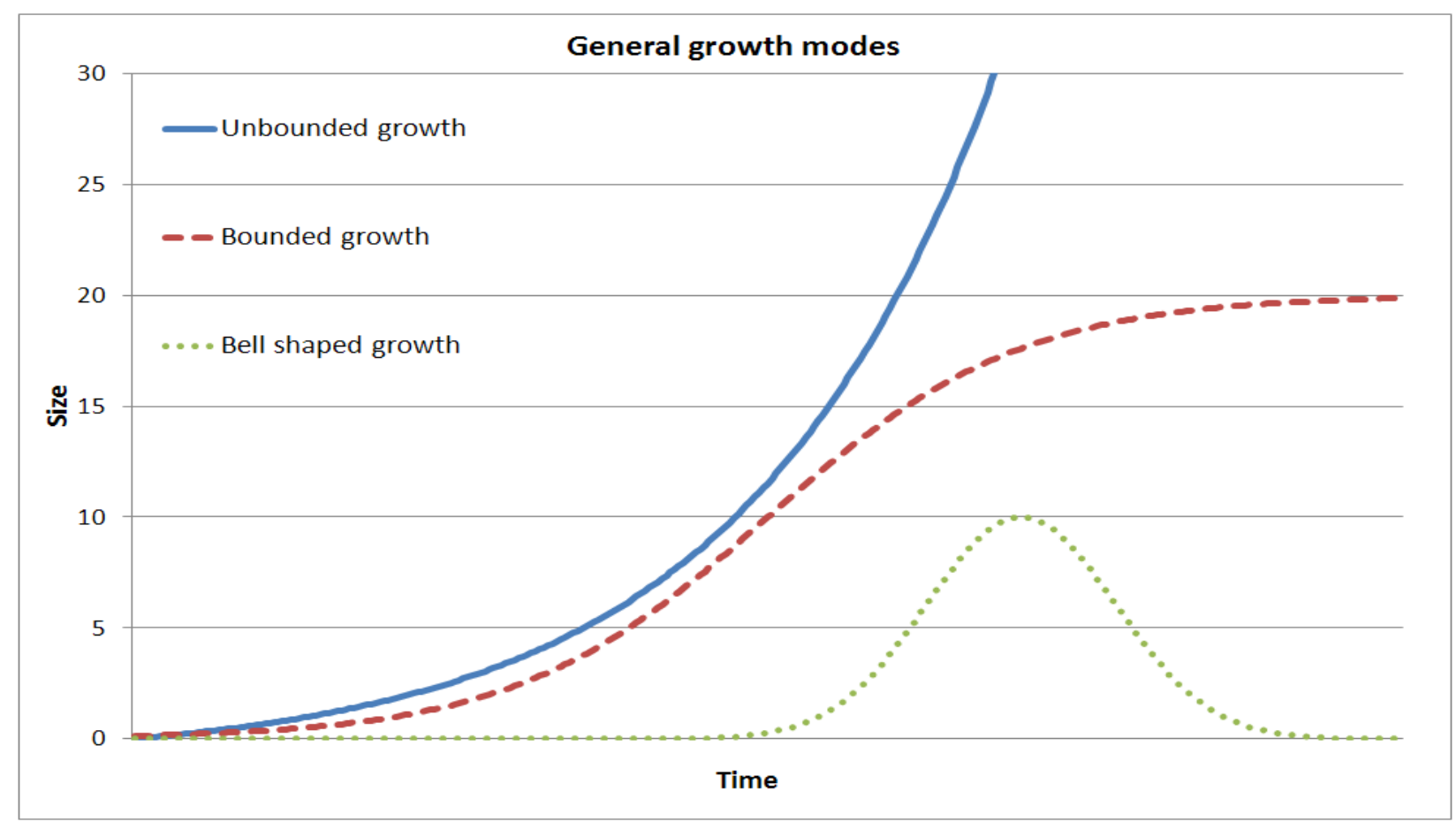

Figure 1: Three different growth modes. Unbounded, bounded and bell-shaped growth behave similarly in the beginning before saturation starts to play a significant role. 


\subsection{Unbounded growth}

All forms of unbounded growth, regardless of its mathematical nature, are clearly not viable in the long-term and will not be discussed in any detail. Linear growth is obviously slower than exponential growth but in the long run all unbounded growths trend towards infinity. Naturally, perpetual growth cannot be used as an underlying assumption for non-renewable energy sources such as fossil fuels.

Even an annual growth of merely $3 \%$, which may be seen as plausible to some can rapidly result in enormous values if it is assumed to continue for a few decades or centuries. However, perpetual growth is often held as an unquestioned belief or even as a fundamental assumption for certain economists. There are even those who claim that the obvious physical limitations of the earth do not necessarily imply an economic limitation (Simon, 1981), or that natural resources are not needed for economic growth (Solow, 1974) or even that human ingenuity can act as a powerful force capable of overcoming all possible physical limitations (Radetzki, 2007). In essence, those ideas must be seen as the belief in unbounded growth.

Rotty (1979) stated that one should be able to make a more accurate analysis than simply projecting continued exponential growth in attempting to estimate future energy demands. Even former technological and economic optimists are now seeing the end of an era with exponential growth (Ayres, 2006). This is hardly surprising, given the underlying arithmetic properties of growth and how quickly unreasonable values are reached for resource production and consumption, even for the most modest of growth rates (Bartlett, 1993; 1999; 2004).

\subsection{Bounded growth}

Another fundamental growth mode is one subjected to limitations that affect growth rates, making growth slow down over time and asymptotically strive towards a maximum value. Growth may actually continue interminably but the rate of growth approaches zero as time tends to infinity. This is well-known in many biological systems where an organism may grow quickly in its juvenile stage but then growth slows down as it reaches maturity.

The limiting factor lies rather in the growth process itself in the form of the increasing monetary, energy or resource costs required for continued expansion. The upper limit may be high, or virtually non-existent, but the steps in development become more and more challenging to take, thus slowing the growth process. In the biological sciences, this is often seen as proportionality between growth rate and actual size or age.

This may be described by bounded exponential growth (Equation 1), sigmoid functions (Equation 2) or similar expressions that may be fitted against either annual or cumulative production data depending on the system studied. For fossil fuels and other finite resources, there is an upper limit in cumulative production caused by geological availability in the earth's crust. Hydropower have no equally well-defined upper limit for cumulative energy production, but may very well be subjected to a numerical bound on the annual production when all suitable rivers have been developed. The important thing is that there is some form of upper limit to the growth process.

$$
y(t)=A(1-\mathrm{a} * \exp (-k t))
$$

If $y(t)$ is used to denote global energy production from an arbitrary energy source at time $t$, then the bounded exponential growth mode has the following properties. It is asymptotic to $q=A$ as $\mathrm{t} \rightarrow \infty$ and monotonously increases with time. Furthermore, it passes through $(0,0)$ 
indicating that energy output starts at zero before utilization of the energy source has begun. Bounded exponential curves grow rapidly in the beginning before slowing down. This type of curve is sometimes called a Brody model, after Brody (1945) who used it to describe growth processes in various biological systems.

Equation 2 shows the Gompertz function, which is one of the many S-shaped curves. In this case, $y(t)$ may denote the global energy production from of arbitrary energy source at time t, and $A$ denotes the saturation level or upper limit. For example, the maximum number of fusion power plants or wind mills that can realistically be constructed in any given area.

$$
y(t)=A * \exp (-a * \exp (-k t))
$$

Compared to bounded exponential curves, sigmoid curves grow slowly in the beginning and end stages, being generally easier to fit to actual implementation of technology and market introduction dynamics. Some of the most well known sigmoid curves are Gompertz curves (Gompertz, 1825), logistic curves (Verhulst, 1838), Bertalanffy curves (Bertalanffy, 1957) and Weibull (1951).

Later, Richards (1959) and Janoschek (1957) developed generalized growth curves that can be used for all forms of bounded growth patterns. Bass diffusion models (Bass, 1969), frequently used in product and technology forecasting, also yield many other sigmoid or bell shaped curves as special cases. Discussions on more generalized growth models can be found in Birch (1999) or Tsoularis and Wallace (2002). Modis (2007) has also written an excellent and amusing overview of the strengths and weaknesses of S-curves. The models described in Equation 1 and 2 should be regarded only as examples, as there are many other mathematical functions capable of describing saturated growth.

Bounded growth curves can be used to model renewable energy sources since some kind of upper limit must exist even for renewable energy. For instance, Berndes et al. (2003) review some limitations for the contribution of biomass to future energy supply. If an upper limit is not assumed, and if an annual doubling of wind power is assumed to continue for 64 years, the situation quickly becomes similar to the wheat and chessboard-problem (Wikipedia, 2010), where unbounded growth leads to totally unrealistic results.

\subsection{Bell shaped growth}

Conceptually, all resources are subjected to a physical limitation, due to the earth's intrinsic finiteness or the limited lifetime of the sun. Such physical resource limitations, primarily the case of finite resources like fossil fuels, affect the general growth pattern. The limitation lies primarily in the maximum cumulative production that can be reached. It is impossible to extract more oil than is contained in an oil reservoir, even though it would, in principle, be possible to dig it all up at once. This limitation predominantly acts on cumulative production and less on the way that maximum cumulative production is reached.

Bell shaped curves have many different shapes and may be symmetric or asymmetric. They are often closely related to sigmoid functions and commonly appear as their derivatives. In other words, they may be seen as annual equivalents to a sigmoid behaviour in a time series of cumulative production data. Bell shaped curves have frequently been used in a wide array of disciplines but initially appear to have developed to describe and predict growth in biological systems or bioenergetics. 
Hubbert (1956) was among the first to formulate a basis for extrapolation of finite resource production curves into the future and bell shaped growth curves were an important cornerstone. He assumed that production levels begin at zero, before production has started, and end at zero, when the resource has been fully exhausted. In between, production would pass through one or several maxima. The actual shape of a given production curve may vary but it is ultimately limited by the recoverable amount of the finite resource in question. In a similar way, general discussion on the production patterns due to the finite nature of a resource has been made by Höök et al. (2010b).

Initially a bell-shaped curve was proposed for idealized production behaviour, representing the various stages of maturity, without giving any exact mathematical description (Hubbert, 1956). Later, Hubbert (1959) used the symmetric logistic function as a tool for creating outlooks after noticing how it agreed well with empirical data on oil discoveries in the USA. The logistic function is given by the differential equation

$$
\frac{d Q}{d t}=b Q\left(1-\frac{Q}{U R R}\right)
$$

Where URR is the ultimately recoverable resource for any finite energy resource, $Q$ denotes the cumulative production, and $d Q / d t$ is the rate of extraction. The constant $b$ governs the growth rate. Physically, one may interpret the logistic equation as a rate of extraction that will initially increase exponentially. Early in the curve the ultimate limit to production is unimportant due to the fact that extracted volumes represent only a small part of the URR. As cumulative production grows and becomes a significant share of the URR, extraction becomes more difficult and the rate of extraction decreases. Since there is an ultimate limit to extractable amounts, production will finally fall to zero. The solution to the logistic equation expresses cumulative production as a function of time and is mathematically represented by

$$
Q(t)=\frac{U R R}{\left(1+\frac{U R R-Q(0)}{Q(0)}\right) \exp (-k t)}=\frac{U R R}{(1+a * \exp (-k t))}
$$

Annual production, denoted by $\mathrm{q}(\mathrm{t})$, at any given period of time can then be calculated from the cumulative production function (shown in Equation 4) by taking the derivative, or using a more simple difference approximation (Equation 5), which will have a bell shaped form.

$$
q(t)=Q(t)-Q(t-1)
$$

Cavallo (2005) performed a closer analysis of Hubberts model and why it was successful in predicting the US peak production in 1970, whilst Carlson (2007) and Brandt (2007) performed general analysis of logistic functions, its derivatives, and related curves. Today, the derivative of the logistic function is called the Hubbert curve in honour of his pioneering work. It is frequently seen in many peak oil discussions. The Hubbert curve shares many properties, such as symmetry, with its parent curve. Closer comparison of logistic curves, Hubbert curves, and similar Gaussian curves have shown that these curve types have a roughly equal descriptive power (Bartlett, 2000; Patzek, 2008). 
Hubbert himself noted that real world production did not need to be symmetric or have a single well-defined maximum. However, most of the framework he developed circumvented the more complex cases and relied on more mathematically tractable curves. In fact, Nehring (2006a, $b, c)$ has noted that the USA comes the closest to a symmetric discovery profile for any major oil producing country or region. Hubbert's focus on the USA and his preference for the symmetric logistic curve and its derivative, i.e. the assumption that the rising tendency will be equally reflected by the post peak decline phase, has been a source of problems. There are no theoretical reasons to expect this symmetry to be a generalised phenomena. Some post-Hubbert modellers have even been known to overuse the symmetric logistic/Hubbert curves, exposing resource constrained modelling to criticism because there are clearly many examples of non-symmetric behaviour.

Bardi (2005), Brandt (2007), and Sorrell and Speirs (2010) highlight some of the problems related to symmetry. More specifically, Bardi (2005) showed that mineral production always results in a bell shaped curve except for very special circumstances. However, Bardi (2005) found that the shape was not necessarily symmetric. Brandt (2007) noted and quantified significant asymmetries in 67 regions between oil production increase and post-peak decline, indicating that less symmetric curves can give better descriptions.

Many asymmetric bell shaped curves with solid foundations exist, but have made little impact on the modelling of energy systems. That is not to say there are no examples of how nonsymmetric growth curves have been used in energy system modelling, but those that do exist appear to have attracted little attention. Moore (1966) and Fitzpatrick et al (1973) used Gompertz curves for analyzing and projecting historical supply patterns of oil and other exhaustible natural resources. The asymmetric HCZ-model (Hu et al., 1995) has been used for petroleum forecasts in China (Feng et al., 2008). Caithamer (2008) introduces a family of exponential power functions with flexible growth rates in both the pre-peak and post-peak regions. However, asymmetric models commonly suffer from being more complex and less straightforward to work with. This complexity is a likely explanation of why they have attracted less attention in recent decades.

The problem of economic considerations has also been debated and extensions to Hubbert's original model (capable of including economics) have been proposed by various studies, such as Kaufmann (1991) or Cleveland and Kaufmann (1991). Lynch (2002) attempts to summarize the economic forecasting methodology and compare it with geophysical growth curve models of Hubbert-type.

An additional property of several bell-shaped curves is the insensitivity of the peak point in relation to the limiting asymptote. Major increases in ultimate reserves shifts the peak point comparatively little in time. This is due to the underlying almost exponential increase depicted in many bell shaped models, such as logistic curves. Miller (1996) gives a striking example of how just a few percent increase in consumption will quickly devour a doubling of the recoverable resources. Sorrell et al. (2010a, 2010b) also present this property and note that the timing of the oil peak is relatively insensitive to assumptions about the size of the resource. 


\section{Examples of growth curves}

Bounded and bell shaped growth should be seen as the only reasonable growth modes in long term outlooks. Unbounded growth is simply physically unfeasible and should be used only for short-term projections. This study presents a simple toolbox containing Brody, Bertalanffy, logistic, and Gompertz functions and examples of their general properties. It should be noted that all of them are special cases of the widely applicable Richards model (Richards, 1959), which is also included. The Richards model and its special cases are shown in Table 1.

Table 1. General properties of selected growth models

\begin{tabular}{lllll}
\hline Model & Equation for $\mathbf{y}(\mathbf{t})$ & $\mathbf{M}$ & Point of inflection & Asymptote \\
\hline Brody & $\mathrm{A}^{*}\left(1-\mathrm{b}^{*} \exp (-\mathrm{kt})\right)$ & 1 & Not defined & $\mathrm{A}$ \\
\hline Bertalanffy & $\mathrm{A}^{*}\left(1-\mathrm{b}^{*} \exp (-\mathrm{kt})\right)^{3}$ & 3 & $8 / 27 \approx 0.30$ & $\mathrm{~A}$ \\
\hline Logistic & $\mathrm{A}^{*}\left(1+\mathrm{b}^{*} \exp (-\mathrm{kt})\right)^{-1}$ & -1 & 0.5 & $\mathrm{~A}$ \\
\hline Gompertz & $\mathrm{A}^{*} \exp (-\mathrm{b} * \exp (-\mathrm{kt}))$ & $\mathrm{M} \rightarrow \infty$ & $\mathrm{e}^{-1} \approx 0.37$ & $\mathrm{~A}$ \\
\hline Richards & $\mathrm{A}^{*}\left(1 \bar{\mp} \mathrm{b}^{*} \exp (-\mathrm{kt})\right)^{\mathrm{M}}$ & Variable & {$[(\mathrm{M}-1) / \mathrm{M}]^{\mathrm{M}}$} & $\mathrm{A}$ \\
\hline
\end{tabular}

Closer discussion of these curves and their derivations can be found in Tsoularis and Wallace (2002). Brody (1945) used a scaling parameter $t_{0}$ to adjust the time scale $\left(t-t_{0}\right)$, so that $b=1$. Similar methodologies or algebraic manipulation may also be applied to rewrite the model equations to generate more practical forms. For example, introducing $t_{0}$ as the peak year and replacing $A$ with a URR-estimate allow a reformulation of the logistic curve (Equation 6) and Gompertz curve (Equation 7) in to clear-cut expressions usable for resource constrained modelling.

$$
\begin{gathered}
y(t)=\frac{U R R}{1+e^{-k\left(t-t_{0}\right)}} \\
y(t)=U R R * e^{-e^{-k\left(t-t_{0}\right)}}
\end{gathered}
$$

The point of inflection occurs when the curvature changes sign, i.e. increase is replaced by decrease. This represents the maximum production point in the model and can be crucial for the choice of model. Suppose the true point of inflection occurs at $20 \%$ of the asymptotic value, but the logistic model, which has its peak point at $50 \%$, is fitted to the data with numerical methods. The result is likely to underestimate (or overestimate) actual production prior to the fitted point of inflection and overestimate (or underestimate) subsequent production. Choosing a model that agrees with the true point of inflection is important since bad choices can introduce systemic errors. This type of criticism has been aimed at the logistic and Hubbert models as they tend to underestimate post-peak production in some regions.

The logistic model is the only symmetric model in Table 1 and the peak occurs when half the ultimate reserves have been produced. Comprehensive studies of giant oil fields, typically holding the majority of oil in many regions, have shown that they peak when approximately $40 \%$ of the URR has been produced (Höök et al., 2009). In addition, Sorrell et al. (2009), using USGS regional data, found that most regions reach their peaks well before half of the URR has been extracted. This indicates that the Gompertz model or other asymmetric models may prove a better choice - at least based on the position of the point of inflection. However, this requires more detailed study. 
All growth rates are largely dependent on the initial (almost exponential) growth rate parameter $k$ that governs the growth pattern before limitations begin to dominate. In short-term outlooks, the differences between a bounded growth curve of sigmoid type and unbounded growth might be very small, but in the long run remarkable differences will appear. In Equation 8 , the first derivative of the Richards function gives a measure of the instantaneous absolute growth rate where the upper sign is valid for $\mathrm{M} \geq 1$ and the lower sign when $\mathrm{M}<0, u=y / A$ is also used for simplicity. The relative growth rate, i.e. a measure of the relative increase from one point in time to the next, can also be derived. Growth rate properties of the selected models are presented in Table 2.

$$
\frac{d y}{d t}= \pm \frac{M k y b e^{-k t}}{1 \mp b e^{-k t}}=M k y\left(u^{-\frac{1}{M}}-1\right)
$$

Table 2. Growth rate properties of selected models. For simplicity, $u=y / A$ is used.

\begin{tabular}{llll}
\hline Model & Equation for $\mathbf{y}(\mathbf{t})$ & Absolute growth rate & Relative growth rate \\
\hline Brody & $\mathrm{A}^{*}\left(1-\mathrm{b}^{*} \exp (-\mathrm{kt})\right)$ & $\mathrm{kA}(1-\mathrm{u}(\mathrm{t}))$ & $\mathrm{k}^{*}\left(\mathrm{u}^{-1}-1\right)$ \\
\hline Bertalanffy & $\mathrm{A}^{*}\left(1-\mathrm{b}^{*} \exp (-\mathrm{kt})\right)^{3}$ & $3 \mathrm{ky}\left(\mathrm{u}^{-1 / 3}-1\right)$ & $3 \mathrm{k}\left(\mathrm{u}^{-1 / 3}-1\right)$ \\
\hline Logistic & $\mathrm{A}^{*}\left(1+\mathrm{b}^{*} \exp (-\mathrm{kt})\right)^{-1}$ & $\mathrm{ky}(1-\mathrm{u})$ & $\mathrm{k}(1-\mathrm{u})$ \\
\hline Gompertz & $\mathrm{A}^{*} \exp \left(-\mathrm{b}^{*} \exp (-\mathrm{kt})\right)$ & $\mathrm{ky} \ln \left(\mathrm{u}^{-1}\right)$ & $\mathrm{k}^{*} \ln \left(\mathrm{u}^{-1}\right)$ \\
\hline Richards & $\mathrm{A}^{*}\left(1 \mp \mathrm{b}^{*} \exp (-\mathrm{kt})\right)^{\mathrm{M}}$ & $\mathrm{Mky}\left(\mathrm{u}^{-1 / \mathrm{M}}-1\right)$ & $\mathrm{Mk}\left(\mathrm{u}^{-1 / \mathrm{M}}-1\right)$ \\
\hline
\end{tabular}

\section{Applications of growth curves}

Growth curve models must be combined with various fitting algorithms for the purpose of analysing a given data set. Arbitrary fitting algorithms may be used to determine the free fitting parameters, such as least squares methods, maximum likelihood or other regression techniques. The Levenberg-Marquardt algorithm (Levenberg, 1944; Marquardt, 1963) is a very popular curve-fitting technique used in many software applications, including MATLAB, Minitab, and SPSS. The Excel Solver is also widely used by many analysts and can handle up to 200 variables. It uses the Simplex routine and branch-and-bound algorithm for linear and integer problems. The Generalized Reduced Gradient (GRG2) nonlinear optimization code (Fylstra et al., 1998) is used by Excel for nonlinear problems (de Levie, 2001; Billo, 2007).

Curve fitting is relatively easy to carry out with modern computer programs and should not be too hard to carry out on arbitrary datasets. Some suitable curve fitting software and the models presented in Table 1 and 2 provide a straightforward toolbox for growth curve fits for models of either the descriptive or predictive type.

Some of the model parameters deserve more attention, especially the asymptote A. There are namely two major kinds of curve fitting that can be done. One is to estimate the URR for a region - where the latter is one of the parameters of the curve, while the second option is to forecast future production from a region, assuming a value for the URR parameter.

The URR is sometimes known, sometimes estimated (depending upon the study), and does not need to be used as a fitting parameter. In the case of fossil fuels, A may be replaced by a priori knowledge about the ultimately recoverable resources (URR) or similar equivalent estimates from suitable geological methods. For biomass and other forms of renewable energies, some estimates of the maximum technical potential are usually available. This reduces the number of free parameters to just two for all models except for the general Richards model. In 
these cases, growth curves can be used to project production patterns into the future. Meyer and Ausubel (1999) also introduced a model extension capable of lifting the upper limit, i.e. a dynamic asymptotic limit that can be used to handle changes over time in the URR estimate.

It is wise to recall that all growth curve models are ideal generalizations of reality and are not able to properly reflect all dynamic processes or short-term fluctuations caused by politics, economics, and similar dynamic perturbations. Modis and Debecker (1992) demonstrate that instabilities associated with production can result in chaos-like states before and after logistic growth and offer several examples of this in industrial production time series for coal and the automotive industry. Milici and Campbell (1997) state that curve fitting should not be seen as a substitute for meticulous economic studies to forecast production over the coming years and decades. Instead, growth curves should be used to provide insight into long-term general trends. Van Rensburg (1975) has also highlighted how growth curves can be used for a simple what-if analysis to investigate what might happen if availability becomes a major constraint.

Oil and other fossil fuels have been frequently subjected to growth curve analysis and various curve fits. The reason for this is most likely the existence of a conceptually clear upper limit, although there has been much discussion about the exact size of the global ultimate reserves. A simple comparison of various curve models applied to the same data set with the same assumption of the upper limit can be seen in Figure 2.

There is also an option to use growth curves to estimate the upper limit for future production, i.e. an assessment of URR. Discoveries of oil and gas are known to follow sigmoid behaviour reasonably well and this has been noted in many studies. It is possible to use the upper limit as a free fitting parameter, thus estimating future discoveries from historical trends. For example, this has been used to forecast future natural gas supply (Laherrère, 2004). Growth curves have also been used to create outlooks for Chinese oil supplies (Tao and Li, 2007). Aleklett and Campbell (2003) presented historical trends in oil discoveries, and showed how an enormous break from trend must occur to fulfil the United States Geological Survey's (2000) estimated discoveries by 2030. Sorrell and Speirs (2010) have reviewed the use of curve fitting models to assess ultimate recoverable resources in more detail.

However, there are pitfalls when using the asymptotic upper limit as a fitting parameter. In the case of Norway and its petroleum discoveries across the entire Norwegian continental shelf, models can provide an excellent fit to historical data (Figure 3), but their upper limit will differ significantly if curve fitting is used to estimate URR. The logistic model gives an URR of $29 \mathrm{~Gb}$, while the Richards model estimates URR to $33 \mathrm{~Gb}$, both approximating the results obtained by other studies based on alternative assessment methods (Höök and Aleklett, 2008 and references within). A Gompertz fit gives an URR of $47 \mathrm{~Gb}$, which appears unreasonably high compared to the other estimates.

The strong agreement between logistic and Richards curves with other assessment methodologies shows that sigmoid functions can be successfully used to project trends into the future that reach a similar conclusion to other techniques. In contrast, the Gompertz fit can serve as an example of how large discrepancies can also appear. The choice of model has significant influence on the outcome if curve fitting is used to estimate the URR. Caution should be exercised and it is often advisable or even necessary to verify the fitted parameters against other studies using different methodologies, rather than simply estimating them from a production time series. 


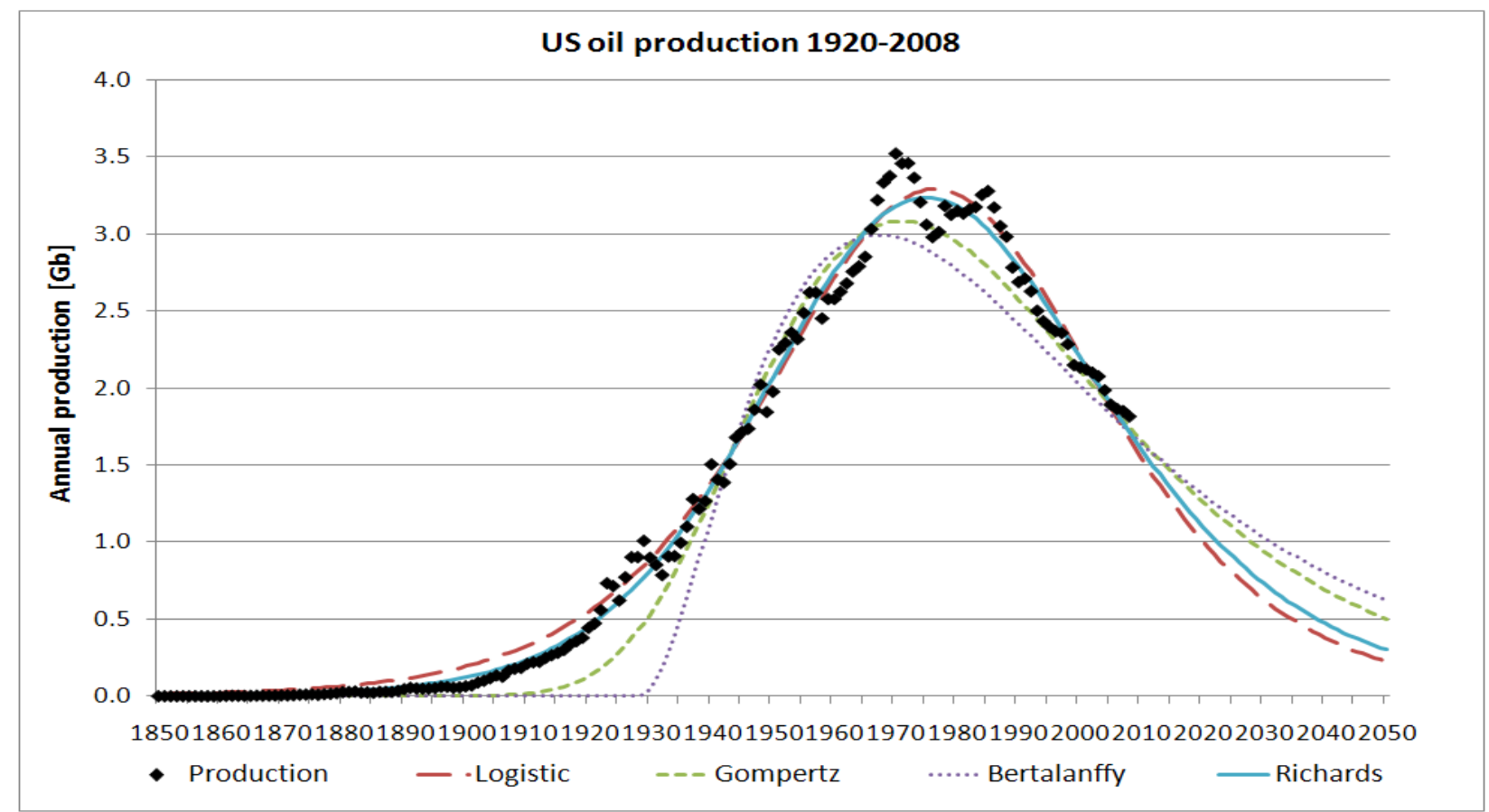

Figure 2: US oil production from 1920 to present, based on production data from EIA (2009) and an assumed URR of $240 \mathrm{~Gb}$. The Richards model and the logistic curves provide the best fits although they tend to underestimate production in recent years. Gompertz and Bertalanffy curves give a less pessimistic outlook for future production but do not properly reflect the production in the beginning of $20^{\text {th }}$ century.

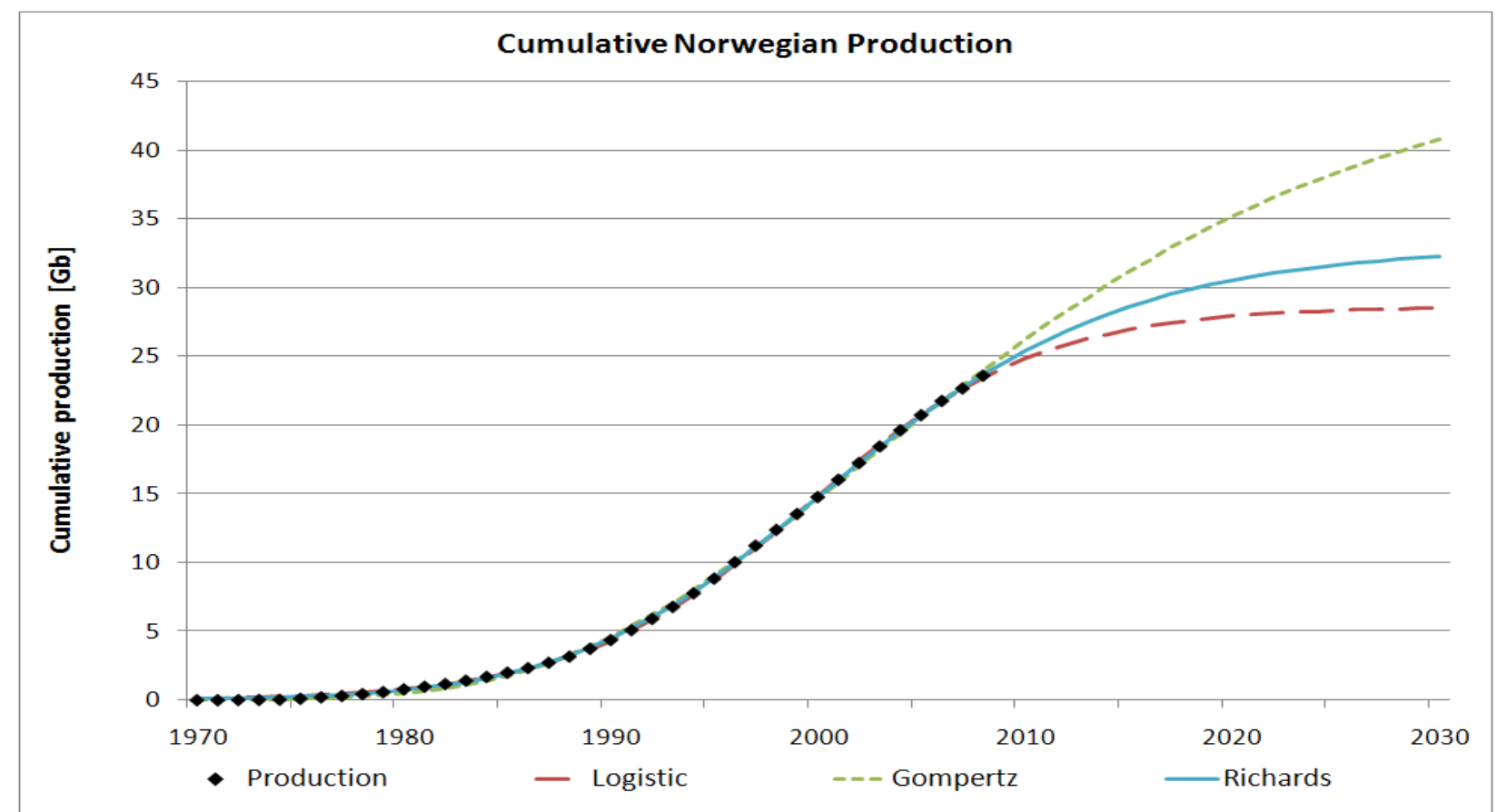

Figure 3: Various sigmoid fits to cumulative Norwegian oil production to estimate ultimate production. All models provide excellent agreement with historical production data but differ significantly in their upper limit. 
Growth curves can also be used to study oil field discovery trends and draw conclusions. A word of caution should first be said about all the intricate, sometimes even confusing, reserve and resource classifications that are available. It has been found that proven+probable (2P) reserve figures are the most realistic estimates of the amounts that can be produced by a number of studies (Bentley et al., 2007; Meng and Bentley, 2008; Owen et al., 2010; Sorrell et al., 2009).

Giant oil fields, i.e. oil fields with more than 500 million barrels of ultimately recoverable resources, are vital to world oil supply and annual discoveries have shown a bell shaped behaviour that peaked in the 1960s (Höök et al., 2009). Their cumulative discovery trend presented in the most recently available $2 \mathrm{P}$ data resembles sigmoid behaviour and fits well with many growth models, especially logistic and Richards curves (Figure 4).

From Figure 4, it can be seen that growth curves can describe this pattern reasonably well. One may even use the strong agreement with fitted curves as a posteriori justification of sigmoid behaviour. However, can this pattern be better understood beyond simple curve fitting? Mann et al. (2003) found $67 \%$ of the worlds giants cluster in 27 regions and that certain geological settings tended to be favoured by giant fields. In essence, few large frontier regions remain for new exploration - mostly just the Arctic and Antarctica. Basically, there are geological reasons to expect that the declining discovery trend will continue (Brown, 2007). As a result, it can make sense to extrapolate this discovery trend curve fit into the future, provided that one has an understanding of the limitations behind this methodology.

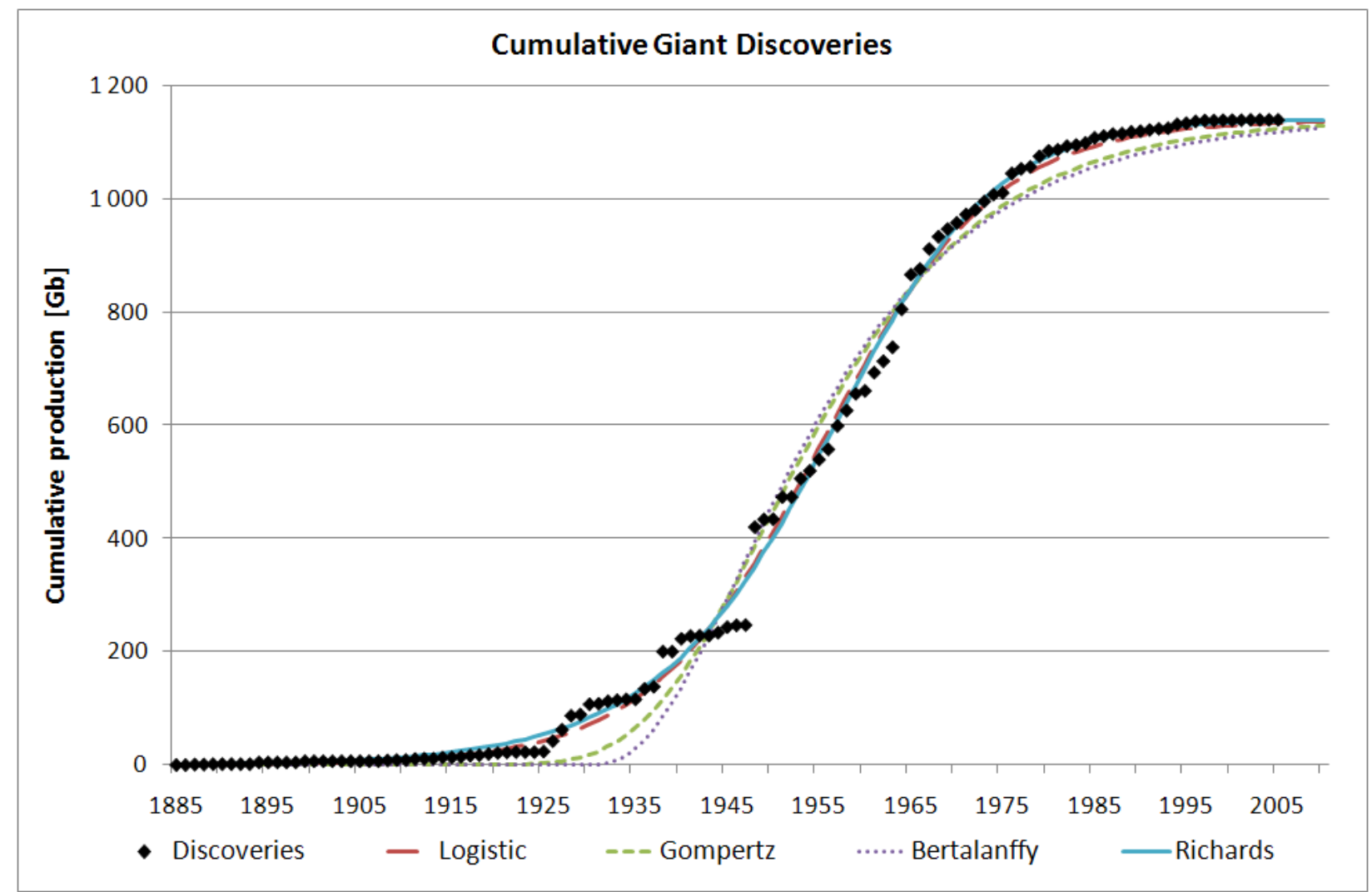

Figure 4: Cumulative discovery trend of 2P data from over 300 giant oil fields based on Höök et al. (2009). Sigmoid behavior is obviously present and corresponds well with both logistic and Richards curves. Unless a completely new discovery cycle appears, few new giants will be discovered in the future. 
Other non-fossil energy sources have also been analyzed or forecast by growth curve methods. Mohamed and Bodger (2004) used logistic curves to depict future outlooks for electricity demand in New Zealand. In a similar way, Mabel and Fernandez (2008) used growth curves to extrapolate trends and showed how $99 \%$ of India's technical wind potential could be reached by 2030 . Regardless of the exact cause of the upper limit, growth curves can be used to provide a reasonable outlook of how future production might unfold when subjected to some limitation. This should also be seen as an example of the general applicability of growth curves to describe or predict growth phenomena under some constraint.

Nuclear power, where social acceptability and political concerns are playing a major role in restraining growth (the addition of new reactors), is one excellent example of how saturation can limit growth. Conceptually, social tolerability is very different from the resource-constraints that limit extraction of fossil fuels. However, the resulting behaviour is strikingly similar and can be described successfully by growth curve models (Figure 5). Until 2020, it appears unlikely that nuclear power generation will move much higher than around $850 \mathrm{TWh}$. Beyond that it is hard to make a long-term forecast since changes in public opinion may significantly increase the upper limit and result in a new period of growth with a corresponding trend shift. Extended growth curve models with dynamic upper limits are available to analysts interested in such outlooks (Meyer and Ausubel, 1999).

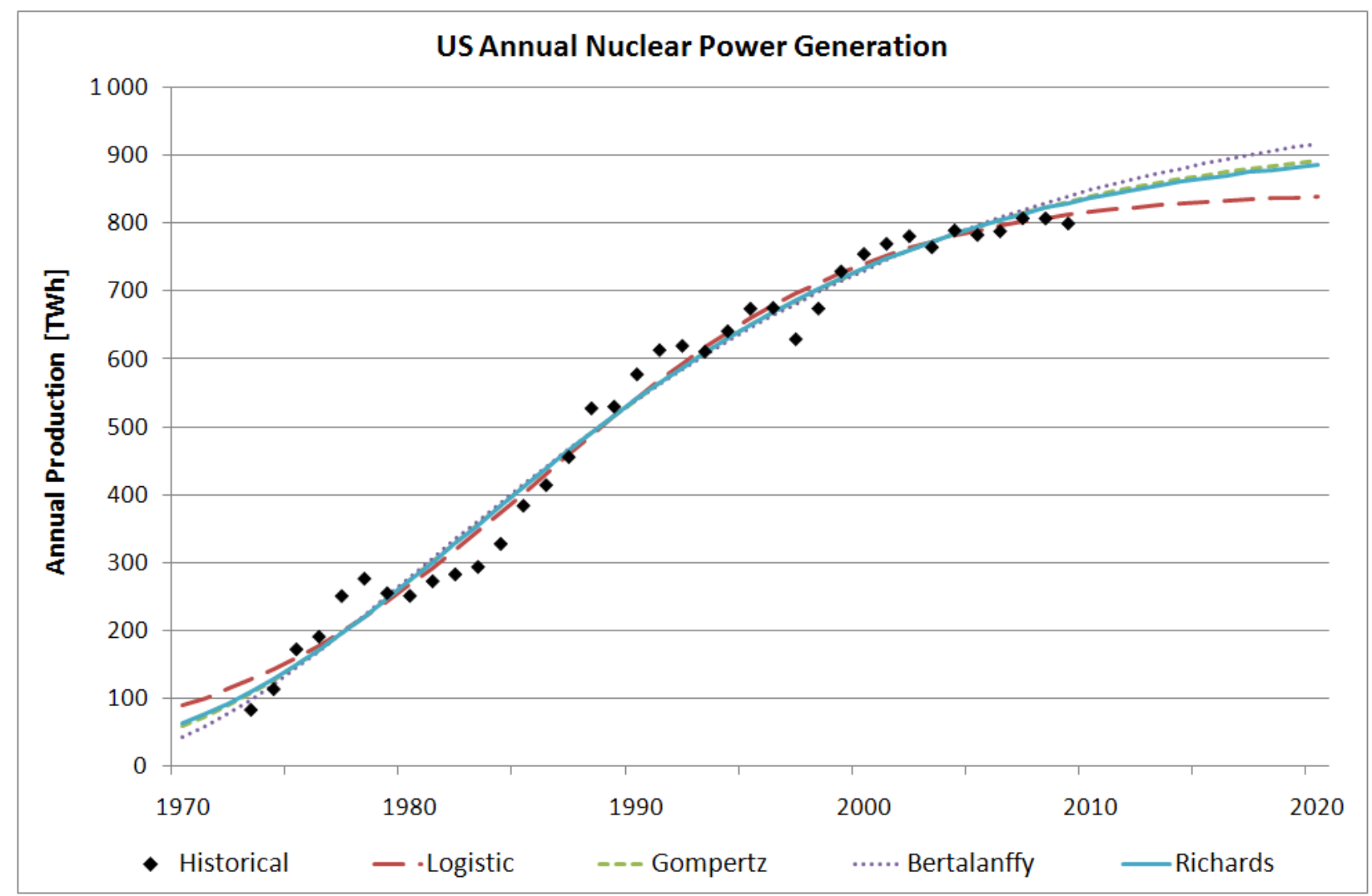

Figure 5: Energy generation of US nuclear power plants from 1973 to 2009 based on data from EIA Monthly Energy Review (2010). Growth curves can successfully describe actual behavior and how growth decreased due to saturation. 
The major benefit of growth curve fit is the direct estimate of the ultimate producible amount, which can be compared or verified by other estimation methods. It should also be noted that critics claim that curve fit does not account for technological or economic factors as possible supply-expansion devices. However, such factors are naturally included in the historical data on which the estimates are based and they are therefore included implicitly. A fact often ignored by critics. On the other hand, there is a possibility that economics or technology will drastically change natural resource production and cause major trend shifts that cannot be foreseen by growth curve fit. However, until there is solid evidence of such significant changes in the system, growth curves appear to be a useful tool for scientists interested in either descriptive or predictive analysis of energy system data.

\section{Concluding discussion}

There are many different curve-fitting models capable of describing or predicting growth ultimately limited by nature. This study has attempted to summarize some basic concepts and provide a simple toolbox based on the Richards model and its special cases for the purpose of easy and straightforward application. Hubbert $(1956,1959)$ and others have proposed mathematical models capable of describing or predicting production where available resources were assumed to be a major constraint. Not only do those models seem theoretically tractable they also agree well with many empirical cases seen in history.

Hotard and Ristroph (1984) showed how economics and technology are implicitly included in the historical data on which growth curves are fitted for prediction of future development. Therefore, growth curves can successfully be used for extrapolation of historical trends and to predict future outcomes as long as there is no significant change in underlying economic and technological conditions. Naturally, there is always the possibility for significant economic or technologic developments that drastically change natural resource production from the way we know it today. However, until these game-changing developments occur, growth curves appear to be a valuable tool for analysts with the task of formulation and implementing natural resource policies. In the end, the forecaster's ultimate test is the accuracy of the forecast - not the ease of application nor the elegance of the method used.

For example, Mohr and Evans (2009) have developed a coal forecasting model based on real world mineral exploitation. Their model resulted in an asymmetric bell shaped production forecast that returns the same outlook as the simple growth curve fit executed by other researchers using equivalent resource constraints (Energywatch group, 2007; Patzek and Croft, 2010; Höök et al., 2010a). This may be seen as an indication that growth curves can be a sound tool capable of yielding results similar to more detailed and complicated models.

However, there are also cases where growth models do not properly describe production. It is also important to remember that these types of curves have their strengths as well as limitations. For instance, growth curve models cannot be more accurate than the data they are applied to. Nor does it seem likely that a model can be perfect and provide the best fit for all possible cases. Laherrère (2000) spoke of the need to use several models and curve fits in a comprehensive study. In the end, the ultimate test of any model is the accuracy of the forecast (Modis, 2007). However, accuracy can only be tested once the future has unfolded. This is well known as "sad but true" for all branches of forecasting and prediction.

Curve fit and growth curve models have been used extensively to model future oil production. The popularity of curve-fitting techniques to estimate URR derives from their simplicity and the relative availability of the required data. However, such estimates are a highly 
debated topic with studies pointing to an imminent resource-constraint (Bentley et al., 2007) or to highly optimistic estimates that claim that oil is more abundant than previously imagined (Watkins, 2006). Proper attention must be paid to the inherent weaknesses of curve-fitting techniques and they should be used in conjunction with other methods for a more holistic approach. Bentley and Boyle (2007), Sorrell and Speirs (2009) and Sorrell et al. (2010b) provide an overview of various forecasting methodologies that have been used.

Regardless of the exact ultimately recoverable volume and the undiscovered reserves, there are some striking facets of future oil supply that should influence long-term planning. Miller (1996) states that "for each recoverable barrel conventionally assumed to remain to be found, the industry has abandoned 10-20 as unrecoverable in known fields" and that "even a doubling of the conventional reserves will not increase their duration if consumption rises by $2 \%$ annually." Based on the arithmetic of growth (Bartlett, 1993, 1999, 2004), it must be concluded that reserve doubling or similar seemingly large increases have little significance for an underlying long-term exponential growth in demand and consumption. This comes from the arithmetic of growth and is generally well reflected by many growth curve models.

In addition, growth curves offer more possibilities than just being an instrument for exposing future expectations. They can also provide a simple tool for resource management to determine what might happen to future production if resource availability poses a problem (van Rensburg, 1975). In the light of peak oil and awareness that natural resources are critical to the continued well-being of society and mankind, resource management should be an important component in planning for a sustainable future.

Moriarty and Honnery (2009) boldly inquired what the energy levels were that the earth could reasonably sustain and highlighted the necessary requirement that fossil fuels are needed to power the shift to renewable or nuclear energy. The emergent use of fossil energy will in all likelihood be limited in all reasonable future scenarios, primarily due to resource limitations or environmental concerns. Consequently, resource management becomes increasingly important in such an environment and growth curves can prove to be an excellent planning tool allowing the application of scenarios with limited resource supply regardless of whether the limitation is geologic or policy-made. Employing suitable growth curves could very well be a simple way of depicting politically imposed limitations of certain energy systems and their development, for example in cases such as a maximum number of nuclear reactors or leaving certain parts of the fossil fuel reserves below ground.

\section{Acknowledgements}

We would like to thank Dr Herbert West for providing valuable inspiration. Two anonymous reviewers also have our sincerest gratitude for presenting comments that greatly improved this manuscript.

\section{References}

Aleklett K, Campbell C, 2003. The peak and decline of world oil and gas production. Minerals and Energy - Raw Materials Report, 18(1), 5-20.

Ang BW, Ng TT, 1992. The use of growth curves in energy studies. Energy, 17(1), 25-36.

Ayres RU, 2006. Turning point: The end of exponential growth? Technological Forecasting and Social Change, 73(9), 11881203.

Bass F, 1969. A new product growth model for consumer durables. Management Science, 15, 215-227.

Bardi U, 2005. The mineral economy: a model for the shape of oil production curves. Energy Policy, 33(1), 53-61. 
Bardi U, 2007. Energy prices and resource depletion: lessons from the case of whaling in the nineteenth century. Energy Sources Part B, Economics, Planning and Policy, 2(3), 297-304.

Bartlett AA, 1993. Arithmetic of growth: methods of calculation. Population and Environment, 14(4), 359-387.

Bartlett AA, 1999. Arithmetic of growth: methods of calculation II. Population and Environment, 20(3), 215-246.

Bartlett AA, 2000. An analysis of U.S. and world oil production patterns using Hubbert-style curves. Mathematical Geology $32(1), 1-17$.

Bartlett AA, 2004. The essential exponential! For the future of our planet. Center for Science, Mathematics and Computer Education, University of Nebraska-Lincoln, $302 \mathrm{p}$.

Bentley R, Mannan SA, Wheeler SJ, 2007. Assessing the date of the global oil peak: The need to use 2P reserves. Energy Policy, 35(12), 6364-6382.

Bentley R, Boyle G, 2007. Global oil production: forecasts and methodologies. Environment and Planning B: Planning and Design, 35(4), 609-626.

Berndes G, Hoogwijk M, van den Broek R, 2003. The contribution of biomass in the future global energy supply: a review of 17 studies. Biomass \& Bioenergy, 25(1), 1-28.

Bertalanffy LV, 1957. Wachstum. In: Helmcke, J.G., Len-Gerken H.V., Starck, D. (Ed.) Handbuch der Zoologie. Walter de Gruyter, Berlin, $68 \mathrm{p}$.

Bickel PJ, Li B, Tsybakov AB, van de Geer SA, Yu B, Valdes T, Rivero C, Fan J, van der Aart A, 2006. Regularization in statistics. TEST, 15(2), 271-344.

Billo, E.J., 2007. Excel for scientists and engineers: numerical methods. Wiley Interscience, New Jersey, 454 p.

Birch CPD, 1999. A new generalized logistic sigmoid growth equation compared with the Richards growth equation. Annals of Botany, 83, 713-723.

Brandt AR, 2007. Testing Hubbert. Energy Policy, 35(5), 3074-3088.

Brody S, 1945. Bioenergetics and growth. Reinhold publishing, New York, $1033 \mathrm{p}$.

Brown D, 2007. World fields study shows trends: giants like stable environments. AAPG Explorer (March 2007): 36-38.

Browne MW, 2000. Cross-validation methods. Journal of Mathematical Psychology, 44(1), 108-132.

Caithamer P, 2008. Regression and time series analysis of the world oil peak of production: another look. Mathematical Geosciences 40(6), 653-670.

Carlson WB, 2007. Analysis of world oil production based on the fitting of the logistic function and its derivatives. Energy Sources Part B: Economics, Planning, and Policy, 2(4), 421-428.

Cavallo AJ, 2004. Hubbert's petroleum production model: an evaluation and implications for world oil production forecasts. Natural Resources Research, 13(4), 211-221.

Chatfield C, 2004. The analysis of time series: an introduction. Sixth edition, CRC press: Boca Raton, $333 \mathrm{p}$.

Clark TE, 2004. Can out-of-sample forecast comparisons help prevent overfitting? Journal of Forecasting, 23(2), 115-139.

Cleveland CJ, Kaufmann RK, 1991. Forecasting ultimate oil recovery and its rate of production: Incorporating economic forces into the models of M. King Hubbert. Energy Journal, 12(2), 17-46.

EIA Monthly Energy Review, 2010. Data taken from http://www.eia.doe.gov/emeu/mer/nuclear.html

Energywatch Group, 2007. Coal: Resources and future production. See also: http://www.energywatchgroup.org/

Feng L, Junchen L, Pang X, 2008. China's oil reserve forecast and analysis based on peak oil models. Energy Policy, 36(11), 4149-4153.

Fitzpatrick A, Hitchon B, McGregor JR, 1973. Long-term growth of the oil industry in the United States. Mathematical Geology, 5(3), 237-267.

Fylstra D, Lasdon L, Warren A, Watson J, 1998. Design and use of the Microsoft Excel Solvers. Interfaces, 28(5), 29-55.

Gompertz B, 1825. On nature of the function expressive of the law of human mortality, and on a new mode of determining the value of life contingencies. Philosophical Transactions of the Royal Society of London, 115, 513-585.

Guyon X., Yao JF, 1999. On the underfitting and overfitting sets of models chosen by order selection criteria. Journal of Multivariate Analysis, 70(2), 221-249.

Hamilton JD, 1994. Time series analysis. First edition. Princeton University Press: New Jersey, 820 p.

Hotard DG, Ristroph JH, 1984. A regional logistic function model for crude oil production. Energy, 9(7), 565-570.

Hu J, Chen Y, Zhang S, 1995. A new model for predicting production and reserves of oil and gas fields. Acta Petrolei Sinica, 16(1), 79-86.

Hubbert MK, 1956. Nuclear energy and the fossil fuels. Presented before the Spring Meeting of the Southern District, American Petroleum Institute, Plaza Hotel, San Antonio, Texas, March 7-9, http://www.hubbertpeak.com/Hubbert/1956/1956.pdf

Hubbert MK, 1959. Techniques of prediction with application to the petroleum industry. Published in 44th Annual Meeting of the American Association of Petroleum Geologists. Shell Development Company, Dallas, TX, 43 p.

Höök M, Aleklett K, 2008. A decline rate study of Norwegian oil production. Energy Policy, 36(11), 4262-4271.

Höök M, Aleklett K, 2009. Historical trends in American coal production and a possible future outlook. International Journal of Coal Geology, 78(3), 201-216.

Höök M, Aleklett K, 2010. Trends in U.S. recoverable coal supply estimates and future production outlooks. Natural Resources Research, 19(3), 189-208.

Höök M, Söderbergh B, Jakobsson K, Aleklett K, 2009. The evolution of giant oil field production behaviour. Natural Resources Research, 18(1), 39-56. 
Höök M, Zittel W, Schindler J, Aleklett K, 2010a. Global coal production outlooks based on a logistic model. Fuel, 89(11), 3546-3558.

Höök M, Bardi U, Feng L, Pang X, 2010b. Development of oil formation theories and their importance for peak oil. Marine and Petroleum Geology, 27(9), 1995-2004.

Imam A, Startzman RA, Barrufet M, 2004. Multicyclic Hubbert model shows global conventional gas output peaking in 2019. Oil \& Gas Journal, 102, 3131-3139.

Janoschek A, 1957. Das reaktionskinetische Grundgesetz und seine Beziehungen zum Wachstums- und Ertragsgesetz. Statistische Vierteljahresschrift, 10, 25-37.

Kaufmann RK, 1991. Oil production in the lower 48 states: reconciling curve fitting and econometric models. Resources and Energy, 13(1), 111-127

Laherrère J, 1997. Multi-Hubbert modeling. http://www.oilcrisis.com/laherrere/multihub.htm accessed 26 May 2010

Laherrère J, 2000. Distribution of field sizes in a petroleum system: parabolic fractal, lognormal or stretched exponential? Marine and Petroleum Geology, 17(4), 539-546.

Laherrère J, 2004. Natural gas future supply. Paper presented at International Energy Workshop jointly organized by the Energy Modeling Forum, International Energy Agency (IEA including ETSAP) and International Institute for Applied Systems Analysis (IIASA), 22-24 June 2004 at the IEA, Paris, France, see also: http://www.iiasa.ac.at/Research/ECS/IEW2004/docs/2004P_Laherrere.pdf

Levenberg K, 1944. A method for the solution of certain non-linear problems in least squares. The Quarterly of Applied Mathematics, 2(2), 164-168.

de Levie, R., 2001. How to use Excel in analytical chemistry and in general scientific data analysis. Cambridge University Press, New York, $487 \mathrm{p}$.

Lynch MC, 2002. Forecasting oil supply: theory and practice. Quarterly Review of Economics and Finance, 42(2), 373-389.

Mabel MC, Fernandez E, 2008. Growth and future trends of wind energy in India. Renewable and Sustainable Energy Reviews, 12(6), 1745-1757.

Mann P, Gahagan L, Gordon MB, 2003. Tectonic setting of the world's giant oil and gas fields. In: Halbouty MT (Ed.) AAPG Memoir 78: Giant oil and gas fields of the decade 1990-1999, p. 15-105.

Marquardt D, 1963. An algorithm for least squares estimation of nonlinear parameters. SIAM Journal on Applied Mathematics, 11(2), 431-441.

McArdle JJ, 2001. Growth curve analysis. In: NJ Smelser, PB Baltes, (Eds), International encyclopedia of the social \& behavioral ciences, Pergamon, Oxford, 2001, Pages 6439-6445.

Meng QY, Bentley RW, 2008. Global oil peaking: Responding to the case for 'abundant supplies of oil'. Energy, 33(8), 11791184.

Meyer PS, Ausubel JH, 1999. Carrying capacity: a model with logistically varying limits. Technological Forecasting and Social Change, 61(3), 209-214.

Milici RC, Campbell EVM, 1997. A predictive production rate life-cycle model for southwestern Virginia coalfields. Geological Survey Circular 1147, 1997, http://pubs.usgs.gov/circular/c1147/

Miller RG, 1996. Estimating global oil resources and their duration. Norwegian Petroleum Society Special Publications, 6, 4356.

Modis T, Debecker A, 1992. Chaoslike states can be expected before and after logistic growth. Technological Forecasting and Social Change, 41(2), 111-120.

Modis T, 2007. Strengths and weaknesses of S-curves. Technological Forecasting and Social Change, 74(6), 866-872.

Mohamed Z, Bodger P, 2004. Forecasting electricity consumption in New Zealand using economic and demographic variables. Energy, 30(10), 1833-1843.

Mohr SH, Evans GM, 2009. Forecasting coal production until 2100. Fuel, 88(11), 2059-2067.

Moriarty P, Honnery D, 2009. What energy levels can the Earth sustain? Energy Policy, 37(7), 2469-2474.

Moore CL, 1966. Projections of U. S. petroleum supply to 1980, with annex entitled: the Gompertz curve for analyzing and projecting the historic supply patterns of exhaustible natural resources, technical report, Office of Oil and Gas, Washington, DC., $47 \mathrm{p}$.

Nashawi IS, Malallah A, Al-Bisharah M, 2010. Forecasting world crude oil production using multicyclic Hubbert model. Energy and Fuels, 24(3), 1788-1800.

Nehring, R., 2006a, Two basins show Hubbert's method underestimates future oil production. Oil \& Gas Journal, 104(13), 3742.

Nehring R, 2006b. How Hubbert method fails to predict oil production in the Permian Basin. Oil \& Gas Journal, 104(15), 3035.

Nehring R, 2006c. Post-Hubbert challenge is to find new methods to predict production. Oil \& Gas Journal, $104(16), 43-46$.

Newton I, 1726. Philosophiae naturalis principia mathematica, general scholium. Third edition, page 943 of I. Bernard Cohen and Anne Whitman's 1999 translation, University of California Press, 974 p.

NIST/SEMATECH, 2010. NIST/SEMATECH e-handbook of statistical methods. See also: http://www.itl.nist.gov/div898/handbook/

Owen NA, Inderwildi OR, King DA, 2010. The status of conventional world oil reserves — Hype or cause for concern? Energy Policy, 38(8), 4743-4749. 
Patzek TW, 2008. Exponential growth, energetic Hubbert cycles, and the advancement of technology. Archives of Mining Sciences, 53(2), 131-159.

Patzek TW, Croft GD, 2010. A global coal production forecast with multi-Hubbert cycle analysis. Energy, 35(8), 3109-3122.

Radetzki M, 2007. Råvarumarknaden (in Swedish), SNS Förlag, 312 p.

Richards FJ, 1959. A flexible growth curve for empirical use. Journal of Experimental Botany, 10(2), $290-301$.

Rotty RM, 1979. Growth in global energy demand and contribution of alternative supply systems. Energy, 4(5), 881-890.

Silvennoinen P, Väänänen J, 1987. Forecasting technological substitution: The logistic model of energy systems revisited. Technological Forecasting and Social Change, 32(3), 273-280.

Simon J, 1998. The Ultimate Resource 2. Revised version, Princeton University Press, 778 p.

Solow R, 1974. The Economics of Resources or the Resources of Economics. American Economic Review. 64(2), 1-14.

Sorrell S, Speirs J, Bentley RW, Brandt AR, Miller RG, 2009. Global oil depletion: an assessment of the evidence for a nearterm peak in global oil production. UK Energy Research Centre, London.

Sorrell S, Speirs J, Bentley RW, Brandt AR, Miller RG, 2010a. Global oil depletion: a review of the evidence. Energy Policy, 38(9), 5290-5295.

Sorrell S, Miller R, Bentley R, Speirs J, 2010b. Oil futures: a comparison of global supply forecasts. Energy Policy, 38(9), 4990-5003.

Sorrell S, Speirs J, 2009. Methods of estimating ultimately recoverable resources. Technical report 5 of the UK Energy Research Centre report on Global Oil Depletion. See also: http://www.ukerc.ac.uk/support/Global\%20Oil\%20Depletion

Sorrell S, Speirs J, 2010. Hubbert's legacy: a review of curve-fitting methods to estimate ultimately recoverable resources. Natural Resources Research, 19(3), 209-230.

Sprott JC, 2003. Chaos and time-series analysis. First edition. Oxford University Press: New York, 507 p.

Stone M, 1978. Cross-Validation: a review. Mathematics of Operations Research and Statistics, 9(1), 127-139.

Szklo A, Machado G, Schaeffer R, 2007. Future oil production in Brazil - estimates based on a Hubbert model. Energy Policy, 35(4), 2360-2367.

Tao Z, Li M, 2007. System dynamics model of Hubbert Peak for China's oil. Energy Policy, 35(4), 2281-2286.

Tsoularis A, Wallace J, 2002. Analysis of logistic growth models. Mathematical Biosciences, 179(1), 21-55.

United States Geological Survey, 2000. World Petroleum Assessment 2000. USGS World Energy Assessment Team, http://pubs.usgs.gov/dds/dds-060/

van Rensburg WCJ, 1975. 'Reserves' as a leading indicator to future mineral production. Resources Policy, 1(6), 343-356.

Verhulst PF, 1838. Notice sur la loi que la population suit dans son accroissement. Correspondence Mathematique et Physique, $10,113-121$.

Watkins GC, 2006. Oil scarcity: What have the past three decades revealed? Energy Policy, 34(5), 508-514.

Weibull W, 1951. A statistical distribution function of wide applicability. Journal of Applied Mechanics, 18(3), $293-297$.

Wikipedia, 2009. Wheat and chessboard problem, available from: http://en.wikipedia.org/wiki/Wheat_and_chessboard_problem 